\title{
Exposure to Aggression in School and Teachers' Intention to Leave Their Profession-A Brief Report
}

\author{
Leehu Zysberg*, Enav Sabbag \\ Gordon College of Education, Haifa, Israel \\ Email: *leehuzysberg@yahoo.com
}

How to cite this paper: Zysberg, L., \& Sabbag, E. (2021). Exposure to Aggression in School and Teachers' Intention to Leave Their Profession-A Brief Report. Psychology, 12, 285-292.

https://doi.org/10.4236/psych.2021.122018

Received: January 15, 2021

Accepted: February 23, 2021

Published: February 26, 2021

Copyright $\odot 2021$ by author(s) and Scientific Research Publishing Inc. This work is licensed under the Creative Commons Attribution International License (CC BY 4.0).

http://creativecommons.org/licenses/by/4.0/

(c) (i) Open Access

\begin{abstract}
Exposure to violence and aggression in the workplace in general and in school in particular has been associated with teacher attrition. However, the underlying processes accounting for this association have not been systematically investigated. This study proposed a mediation model accounting for the above association through the involvement of stress. One hundred and eighty-eight teachers from schools all over northern Israel $(92 \%$ women; mean age $=$ 43.64; sd $=9.58$ ) filled out measures of exposure to aggression (physical and verbal), demographics, a stress questionnaire, and a brief questionnaire assessing intentions to leave the teaching profession. Path analysis supported a mediation model in which stress levels mediated the association between exposure to physical aggression, followed by exposure to verbal aggression and age and intentions to leave teaching. The results are discussed in light of the existing empirical evidence and theory.
\end{abstract}

\section{Keywords}

Aggression, Verbal Aggression, Physical Aggression, Stress, Leaving Intentions

\section{Introduction}

Aggression toward teachers in schools is a subject that has garnered recent attention in educational research (e.g.: McMahon et al., 2020; Moon and McCluskey, 2020). While the phenomenon appears to be quite frequent in school settings, there is less research focusing on this type of aggression, compared with aggression aimed at students and pupils. The importance and relevance of this social-psychological phenomenon is self-evident: numerous studies point to the adverse effects of exposure to aggression and violence in school settings, espe- 
cially for pupils, but also other members of the school community (Patton et al., 2012). This study addressed the phenomenon, by examining the association between teachers' exposure to aggressive behavior (verbal and physical) and their intentions of leaving the teaching profession.

Aggressive behavior directed at schoolteachers was found to mainly involve theft of personal belongings, physical aggression, sexual harassment, as well as verbal abuse, and threats (Moon et al., 2019). Other sources describe aggression that may not be originally aimed at teachers but eventually experienced by themin such cases where they break up fights or try to settle conflicts among students or others (McMahon et al., 2020). In general verbal aggression seems to be more common in schools than physical aggression or physical threats.

Only a handful of studies seriously address the wide range of consequences of such exposure to violence and aggression: McMahon et al. (2020) gleaned a view of the experience of exposure to different types of aggression, the way it is being handled and some of the psychological and emotional consequences of such experience in a qualitative study of a large sample of teachers in the US. Berg and Cornell (2016) described one of the most common outcomes of exposure to aggression in schools as distress. Others describe the outcomes of such exposure for teachers in similar terms: lower connectedness to the school environment, lower job satisfaction, victimization and thoughts of leaving the profession (Curran et al., 2019; Moon et al., 2019). While the associations among exposure to aggression and various teachers' work outcomes are well established, less is known of the paths and processes underlying these associations. This study attempted to propose and test such a model accounting for association between exposure to different types of aggression in school (verbal and physical) and teachers' intentions of leaving the teaching profession, based on a basic theoretical model of stress exposure.

\section{Exposure to Aggression, Stress, and Intentions of Leaving}

Aggression is most often interpreted as a threat, thus eliciting a "fight of flight" stress reaction (O’Dea et al., 2017). In other words-stress reaction is the most common pattern of response to threat or aggression, and in survival terms it makes a lot of sense-the stress reaction allows individuals and groups to regroup in the face to threat or opportunity, manage resources effectively to either mitigate or evade the threat (Silove, 1998). However, as exposure to threat increases, and stress is amplified or extended through a prolong period-stress will take a higher and higher toll on individuals and groups.

The effects of stress on individual wellbeing are well documented (Aneshensel, 1999): The physiological aspects of the stress are often associated with endocrinological imbalances originally aimed at preparing us for action (fight or flight) that may lead to a marked decrease in the immune system function, chronic and opportunistic health conditions that may result from such imbalance. In addition, stress has been consistently associated with a broad range of psychological outcomes. These range from cognitive symptoms-characterized by a decrease 
in attention, focus, effectiveness of data analysis and emotional conditions ranging from negative mood to burnout and depression (Hammen, 2005).

Individual responses to stress vary dramatically but may be crudely categorized into two major patterns mentioned above: "fight"-act to eliminate or overcome the perceived source of stress, or "flight"-avoid the threat. Within this context, intention to leave the profession may be defined as an avoidance behavior, aimed at self-preservation through evading the source of stress. In work settings, employee tardiness, absenteeism and turnover are considered avoidance behavior and are often associated with employee stress (Manning \& Osland 1989; Ybema et al., 2010).

Thus, it is theoretically consistent with the existing literature on stress, to hypothesize that exposure to threat (i.e.: acts of verbal or physical aggression aimed toward teachers) will elicit stress response and stress, in turn will elicit an avoidance response-namely-show intentions to leave the teaching profession. Figure 1 provides a graphic summary of our study hypotheses.

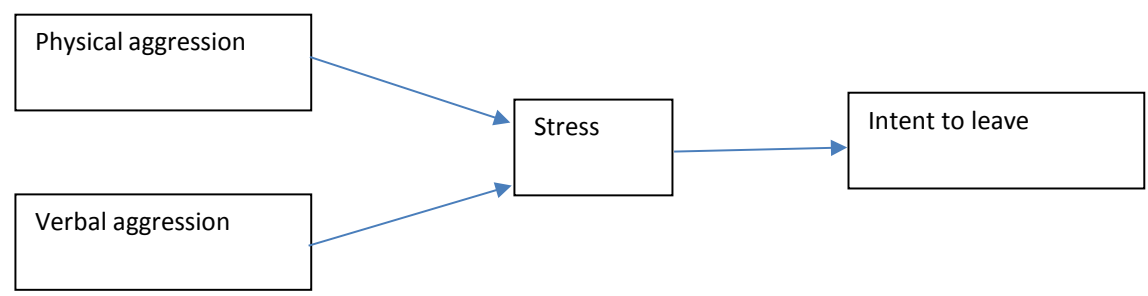

Controlling for demographics: Gender, age, tenure.

Figure 1. A summary of the study hypotheses.

\section{Method}

\subsection{Settings and Sample}

We recruited participants from state schools located in northern Israel (before the outbreak of COVID-19). One hundred and eighty-eight teachers, working in state schools in northern Israel filled out our questionnaires, of them $92 \%$ were women, and the mean age was $43.64(\mathrm{sd}=9.58)$. All had at least a bachelor's degree (about half had a Masters' degree) the mean tenure on the job was 16.05 (sd $=10.85$ ) years. The sample was recruited in two waves from various social networks frequented by teachers in Israel. As a sample they are quite representative of the general population of state-school teachers in Israel with the exception of education level which was somewhat higher (Israel ministry of education, 2020).

\subsection{Measures}

Exposure to aggression in school was assessed using a self-report scale developed by McMahon, Martinez, Espelage et al., (2014). This is an 11-item scale yielding 2 subscales for physical and verbal aggression used to assess the amount 
of exposure to these types of violence. Existing studies found acceptable levels of reliability ranging $.87-.85$ for the subscales

Stress was assessed using the perceived stress scale (PSS, Cohen, Kamaeck \& Mermelstein, 1983). This 14-item scale shows adequate psychometric properties with reliability ranging $.82-.87$ in reported studies.

Intention to leave teaching was assessed using a single item asking participants to assess to what extent did they consider leaving their job in the last months. The response if provided on a simple Likert scale ranging 1 (not at all) to 5 (very much so). This method is widely acceptable as a simple and straight forward manner of assessing employees' intention of leaving their job (e.g.: Van Schalkwyk et al., 2010).

Demographics such as age, tenure, education level, and gender were also collected.

\subsection{Procedure}

The study plan was approved by the authors' IRB. Potential participants were approached using various social networks used by teachers and through acquaintances with the authors. Participants were asked to forward the link to other teachers who met the inclusion criteria. Filling out questionnaires took about 10 - 13 minutes. Recruitment was conducted in two waves with a 3 month interval.

\section{Results}

Before testing our model, we examined the distributions of our focal variables. The results are summarized in Table 1 herein.

The indices show reasonable distributions with no floor or ceiling effects, and adequate reliability coefficients for all scales.

We then proceeded to examine preliminary associations among the study variables using simple zero order correlations. These are reported in Table 2 herein.

The correlation matrix shows that all our focal variables were interconnected. However, the associations of most interest are those among exposure to both types of aggression and stress, as well as intentions of leaving. Interestingly age was negatively associated with all the other outcomes.

To test our model, we used path analysis in AMOS 24.0. The results of the analyses are summarized in Figure 2.

Table 1. Descriptive statistics for the study variables $(n=188)$.

\begin{tabular}{cccccc}
\hline & Mean & SD & Min. & Max. & Cronbach's alpha \\
\hline Intentions of leaving & 2.29 & 1.31 & 1.00 & 5.00 & -- \\
Stress & 2.14 & .41 & 1.25 & 3.80 & .78 \\
Verbal aggression & .34 & .48 & 0.00 & 1.00 & .68 \\
Physical aggression & .27 & .44 & 0.00 & 1.00 & .83 \\
\hline
\end{tabular}


Table 2. Correlations among the study variables $(n=188)$.

\begin{tabular}{lccccc}
\hline & 1 & 2 & 3 & 4 & 5 \\
\hline 1. Stress & - & & & & \\
2. Verbal aggression & $.46^{* *}$ & - & & & \\
3. Physical aggression & $.50^{\star *}$ & $.84^{* *}$ & - & & \\
4. Intentions of leaving & $.49^{* *}$ & $.26^{*}$ & $.31^{\star *}$ & - & \\
5. Age & $-.29^{* *}$ & $-.22^{*}$ & $-.27^{* *}$ & $-.31^{* *}$ & - \\
\hline
\end{tabular}

${ }^{*} p<.05{ }^{* *} p<.01$.

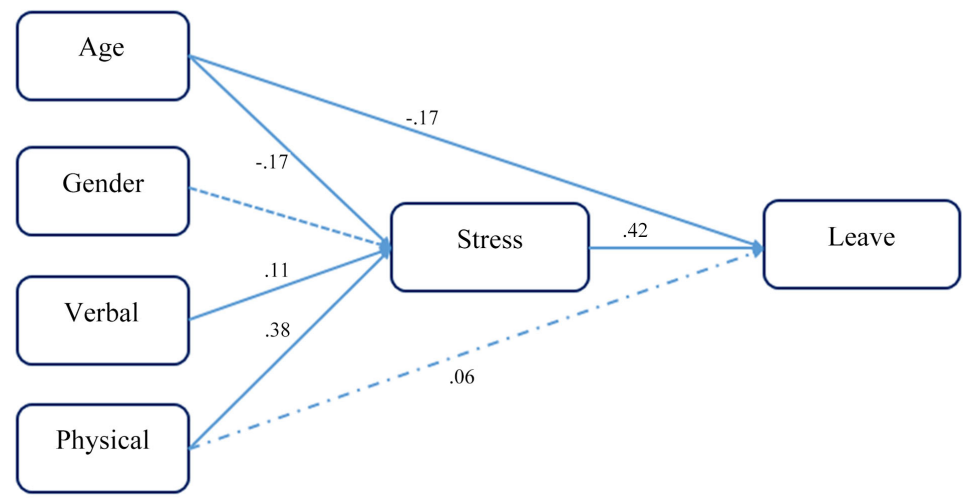

Figure 2. A summary of the empirical path model. Goodness of fit indices and indirect effect summary are as follows $\left({ }^{\star} p<.05{ }^{\star *} p<.01\right)$ : Chi-square $=6.94 ; \mathrm{df}$ $=3, p>.05, \mathrm{NFI}=.96$; CFI $=.97$; RMSEA $=.07$, Physical aggressionStress-Intentions of leaving $=.17,{ }^{*}$ Verbal aggression-Stress-Intentions of leaving $=.05$, Age-Stress-Intentions of leaving $=-.07^{\star}$.

The figure presents the final, empirical model after deletion of non-significant paths. We also deleted the error terms for the sake of clarity of presentation. The empirical model provides partial support to our original hypothesized model suggesting that the association between exposure to physical (and marginallyverbal) aggression and intentions of leaving the teaching profession is mediated by the sense of stress experienced by the teacher. Age showed a dual (mediated and direct) negative effect on stress and intentions of leaving. It was also the only background variables to be included in the final model.

\section{Discussion}

Teacher everyday reality in the schools is complex and imbued with challenges, and a major component of these challenges is the need to cope with aggression aimed at them from pupils (Longobardi et al., 2019). This challenge remains valid even in online learning settings, as evidenced by studies conducted during the COVID-19 crisis (e.g.: Dolev-Cohen and Levkovich, 2020). This exposure to both verbal and physical aggression is associated with a vast range of adverse outcomes among teachers the world over, among them is the tendency and the intention to leave the teaching profession (Albright et al., 2017). Education sys- 
tems invest time and funds preparing the training teachers and such turnover has a detrimental effect not only on the pupils and teachers in the schools where teachers leave-but also on the national level (Sorensen and Ladd, 2020). While the association between the two phenomena is well documented, less is known about processes and mechanisms that underlie it.

Our study proposed a model in which stress mediates the association between exposure to aggression (verbal and physical) and intentions of leaving. Our results, based on data provided by a sample of schoolteachers in northern Israel, provide partial support to the proposed model. We found a positive mediated association in which exposure to physical violence increases stress and stress associated with intentions of leaving the teaching profession. Interestingly the mediated effect of verbal aggression was only marginally significant. In addition, age associated negatively with stress and intentions of leaving (in both a mediated and direct effect).

The results presented here are congruent with what we know of how aggression affects individuals and groups and in turn how stress shapes organizational behavior: exposure to aggression elicits and semi-automatic sympathetic response pattern - the "fight or flight" response that involves the experience of stress-a multi-systemic response preparing us to respond-wither protect and defend or escape and evade the threat (McCarty, 2016). In other words-stress responses are the most immediate and natural responses to exposure to threat (and thus it also accounts for why the effect route for physical aggression was more pronounced than the one involving verbal aggression). The nearly automatic "fight or flight" response will force teachers to choose between two ways of actionrespond to aggression with aggression-which is of course not a possibility in educational settings, or "flight"-escape and evade the threat. This leads us to a better understanding of the intentions of leaving in teachers exposed to aggression in their work: in the absence of a systemic solution, as stress accumulatestheir only viable response is to withdraw or leave.

While our results point to possible directions of theoretical and practical implications, the readers should bear in mind the study limitations: Our sample was taken solely from northern Israel, and while it is a geographic area with diverse populations, cultural, political and additional aspects may limit the generalizability of our results. The use of self report measures has its own advantages but also drawbacks and biases that should be kept in mind. Future studies may examine the model in different cultures and education systems and consider including observational data in their design.

\section{Recommendations for Practice}

Should additional evidence support our model, such psychological insights regarding the route through which exposure to aggression may lead teachers to consider leaving their profession may help educators and educational policy makers alike take steps to reduce aggression in schools on the systemic level, thus indirectly reducing teacher turnover. Interventions may include tools and tech- 
niques for more effective stress management, creating organizational and psychological barriers to explicit aggression (especially physical, based on our results).

\section{Conflicts of Interest}

The authors declare no conflicts of interest regarding the publication of this paper.

\section{References}

Albright, J. L., Safer, L. A., Sims, P. A., Tagaris, A., Glasgow, D., Sekulich, K. M., \& Zaharis, M. C. (2017). What Factors Impact Why Novice Middle School Teachers in a Large Midwestern Urban School District Leave after Their Initial Year of Teaching. International Journal of Educational Leadership Preparation, 12, 1-16.

Aneshensel, C. S. (1999). Outcomes of the Stress Process. In A. V. Horwitz, \& T. L. Scheid (Eds.), A Handbook for the Study of Mental Health: Social Contexts, Theories, and Systems (pp. 211-227). Cambridge: Cambridge University Press.

Berg, J. K., \& Cornell, D. (2016). Authoritative School Climate, Aggression toward Teachers, and Teacher Distress in Middle School. School Psychology Quarterly, 31, 122. https://doi.org/10.1037/spq0000132

Curran, F. C., Viano, S. L., \& Fisher, B. W. (2019). Teacher Victimization, Turnover, and Contextual Factors Promoting Resilience. Journal of School Violence, 18, 21-38. https://doi.org/10.1080/15388220.2017.1368394

Dolev-Cohen, M., \& Levkovich, I. (2020). Teachers' Responses to Face-to-Face and Cyberbullying of Colleagues by Others in Israeli Schools. International Journal of School \& Educational Psychology, 1-13. https://doi.org/10.1080/21683603.2020.1772159

Hammen, C. (2005). Stress and Depression. Annual Review of Clinical Psychology, 1, 293-319. https://doi.org/10.1146/annurev.clinpsy.1.102803.143938

Israel Ministry of Education (2020). Teachers' Day: Data and Descriptive Demographics. (In Hebrew) https://www.maariv.co.il/news/Education/Article-807291

Longobardi, C., Badenes-Ribera, L., Fabris, M. A., Martinez, A., \& McMahon, S. D. (2019). Prevalence of Student Violence against Teachers: A Meta-Analysis. Psychology of Violence, 9, 596. https://doi.org/10.1037/vio0000202

Manning, M. R., \& Osland, J. S. (1989). The Relationship between Absenteeism and Stress. Work \& Stress, 3, 223-235. https://doi.org/10.1080/02678378908251558

McCarty, R. (2016). The Fight-or-Flight Response: A Cornerstone of Stress Research. In Stress: Concepts, Cognition, Emotion, and Behavior (pp. 33-37). Cambridge, MA: Academic Press. https://doi.org/10.1016/B978-0-12-800951-2.00004-2

McMahon, S. D., Martinez, A., Espelage, D., Rose, C., Reddy, L. A., Lane, K., Anderman, E. M., Reynolds, C. R., Jones, A., \& Brown, V. (2014). Violence Directed against Teachers: Results from a National Survey. Psychology in the Schools, 51, 753-766. https://doi.org/10.1002/pits.21777

McMahon, S. D., Peist, E., Davis, J. O., Bare, K., Martinez, A., Reddy, L. A., Anderman, E. M. et al. (2020). Physical Aggression toward Teachers: Antecedents, Behaviors, and Consequences. Aggressive Behavior, 46, 116-126. https://doi.org/10.1002/ab.21870

Moon, B., \& McCluskey, J. (2020). An Exploratory Study of Violence and Aggression against Teachers in Middle and High Schools: Prevalence, Predictors, and Negative Consequences. Journal of School Violence, 19, 122-137. 
https://doi.org/10.1080/15388220.2018.1540010

Moon, B., McCluskey, J., \& Morash, M. (2019). Aggression against Middle and High School Teachers: Duration of Victimization and Its Negative Impacts. Aggressive Behavior, 45, 517-526. https://doi.org/10.1002/ab.21840

O’Dea, C. J., Bueno, A. M. C., \& Saucier, D. A. (2017). Fight or Flight: Perceptions of Men Who Confront versus Ignore Threats to Themselves and Others. Personality and Individual Differences, 104, 345-351. https://doi.org/10.1016/j.paid.2016.08.040

Patton, D. U., Woolley, M. E., \& Hong, J. S. (2012). Exposure to Violence, Student Fear, and Low Academic Achievement: African American Males in the Critical Transition to High School. Children and Youth Services Review, 34, 388-395.

https://doi.org/10.1016/j.childyouth.2011.11.009

Silove, D. (1998). Is Posttraumatic Stress Disorder an Overlearned Survival Response? An Evolutionary-Learning Hypothesis. Psychiatry, 61, 181-190.

https://doi.org/10.1080/00332747.1998.11024830

Sorensen, L. C., \& Ladd, H. F. (2020). The Hidden Costs of Teacher Turnover. AERA Open, 6, 2332858420905812. https://doi.org/10.1177/2332858420905812

Van Schalkwyk, S., Du Toit, D. H., Bothma, A. S., \& Rothmann, S. (2010). Job Insecurity, Leadership Empowerment Behaviour, Employee Engagement and Intention to Leave in a Petrochemical Laboratory. SA Journal of Human Resource Management, 8, 7. https://doi.org/10.4102/sajhrm.v8i1.234

Ybema, J. F., Smulders, P. G., \& Bongers, P. M. (2010). Antecedents and Consequences of Employee Absenteeism: A Longitudinal Perspective on the Role of Job Satisfaction and Burnout. European Journal of Work and Organizational Psychology, 19, 102-124. https://doi.org/10.1080/13594320902793691 